\title{
Haemodynamic and energetic properties of stunned myocardium in rabbit hearts
}

Jochen D Schipke, Bernhard Korbmacher, Anja Dorszewski, Gündüz Selcan, Ulrich Sunderdiek, Gunther Arnold

\begin{abstract}
Objective-To amplify the description of myocardial stunning.
\end{abstract}

Design-Control versus $30 \mathrm{~min}$ after a 20 min no flow ischaemia.

Experimental animals -15 isolated rabbit hearts perfused with erythrocyte suspension.

Main outcome measures-Left ventricular systolic function in terms of aortic flow, peak systolic pressure (LVPmax), dP/dtmax, and the end systolic pressurevolume relation (ESPVR); early relaxation from dP/dtmin and rate of left ventricular pressure decay $(\tau)$. Passive properties: ventricular and myocardial stiffness. Coronary resistance from coronary blood flow and perfusion pressure. Total myocardial oxygen consumption (MVo $\mathrm{M}_{2}$ tot). Total mechanical energy via pressure-volume area (PVA). Contractile efficiency (Econ) and $\mathrm{MVO}_{2}$ of the unloaded contracting heart ( $M \mathrm{YO}_{2} \mathrm{unl}$ ). External mechanical efficiency (Eext) from stroke work and $\mathrm{MVO}_{2}$ tot.

Results-Systolic variables in stunned myocardium were significantly decreased (mean (SD)): aortic flow: 38 (13) $v 9$ (11) ml/min; LVPmax: 112 (19) $v 74(18) \mathrm{mm}$ Hg; dP/dtmax: 1475 (400) $v 1075$ (275) mm Hg/s. ESPVR was not significantly decreased, at $138(73) \quad v 125(58) \mathrm{mm}$ $\mathrm{Hg} / \mathrm{ml}$, but the volume axis intercept was shifted rightward: $0.30(0.37) v 0.65(0.25)$ ml. Likewise, early relaxation was impaired: dP/dtmin $(-1275$ (250) $v-975$ (250) $\mathrm{mm} \mathrm{Hg} / \mathrm{s}$ ) and $\tau$ (37 (7) $v 46$ (10) ms). LVPed was significantly decreased at 19 (12) $v 12$ (7) $\mathrm{mm} \mathrm{Hg}$, and both the ventricular (end diastolic pressure-volume relation) and the myocardial stiffness (constant $k$ ) were increased by $75 \%$ and $31 \%$, respectively. Coronary resistance increased non-significantly from 0.83 $(0.31)$ to $1.04(0.41) \mathrm{mm} \mathrm{Hg} /(\mathrm{ml} / \mathrm{min} / 100$ g). Decreases in PVA (570 (280) $v 270$ (200) $\mathrm{mm} \mathrm{Hg} \cdot \mathrm{ml} / 100 \mathrm{~g}), \mathrm{MVO}_{2}$ tot $(40$ (9) $v$ 34 (8) $\mu \mathrm{l} / \mathrm{beat} / 100 \mathrm{~g}$ ), and $\mathrm{MVo}_{2} \mathrm{unl}$ (26 (9) $v 22(6) \mu 1 / b e a t / 100 \mathrm{~g})$ did not reach significance, in contrast to significant decreases in Econ (31 (18) $v 14(7) \%)$ and Eext $(0.75(0.29) \quad v \quad 0.18(0.25)$ arbitrary units).

Conclusions-Ventricular systolic function is decreased after brief episodes of ischaemia. The decrease in diastolic function probably amplifies the systolic dete- rioration during myocardial stunning. Passive diastolic properties are also changed, shown by increases in both ventricular and myocardial stiffness. The increase in coronary resistance indicates stunning at the vascular level which could limit oxygen supply. With maintained $\mathrm{MVo}_{2}$ tot during stunning, external efficiency is decreased. Possible candidates for this metabolic stunning are inadequate excitation-contraction coupling and disturbed $\mathrm{O}_{2}$ utilisation by the contractile apparatus.

(Heart 1996;75:55-61)

Keywords: stunning; coronary resistance; efficiency; isolated heart

After brief periods of ischaemia, myocardial function remains depressed for hours or even days. This is known as myocardial stunning. ${ }^{12}$ Although there are many published reports on myocardial stunning, ${ }^{3-5}$ the phenomenon is far from completely understood. Many of the studies focus only on systolic properties ${ }^{6-8}$ as one aspect of that particular myocardial state.

Depending on the duration and severity of the ischaemic insult, postischaemic myocardium can become entirely ${ }^{2}$ or almost entirely akinetic. ${ }^{910}$ In the present study, we reveal some effects on diastolic properties that are similarly impaired after relative short periods of ischaemia ${ }^{11-13}$ and could have a common basis with systolic properties at a cellular level. ${ }^{9}$ Thus changes in mechanical properties were also assessed in this study. The vascular system is additionally affected in the stunned myocardium, and endothelial cell injury, ${ }^{14}$ increased capillary permeability, ${ }^{15}$ reduced reactive hyperaemia, ${ }^{16}$ prolonged increase in coronary resistance, ${ }^{17} 18$ or development of the no reflow phenomenon ${ }^{19}$ were reported. Although ventricular function is depressed, oxygen consumption in the stunned myocardium is normal or close to normal. ${ }^{162021}$ Hence the stunned myocardium is inefficient. To describe not only one aspect of myocardial stunning but this altered state as an entity, experiments were performed in isolated, blood perfused rabbit hearts, and haemodynamic and metabolic variables were assessed during normal perfusion and during reperfusion after global ischaemia. 


\section{Methods}

EXPERIMENTAL PREPARATION

Experiments were performed on 15 male New Zealand White rabbits with an average age of 6 months and an average weight of 2300 (SD 200) $\mathrm{g}$; the rabbits were handled according to the animal welfare regulations of the federal authorities. To avoid any ischaemic insult that could precondition the myocardium, the hearts were connected to a modified Langendorff setup after rapid excision, and continuously perfused at normothermia. Bovine erythrocytes were added to the modified Krebs-Henseleit solution (11 mM glucose) so that the packed cell volume was $30 \%$. The solution contained $4 \mathrm{~g} / 100 \mathrm{ml}$ albumin, and the calcium concentration was $3.6 \mathrm{mM}$. Oxygenation of the recirculating erythrocyte suspension was achieved using a paediatric hollow fibre oxygenator (Masterflo 34, Dideco). The perfusate temperature was held at $37^{\circ} \mathrm{C}$, and the coronary arterial pressure was maintained at desired levels using a servo controlled roller pump.

A water filled latex balloon (No 14-16, H Sachs Elektronik) was inserted into the left ventricular cavity through the mitral valve. The balloon was connected to a "systemic" circuit that contained two artificial valves and a Windkessel. An ultrasonic flow probe in connection with a flowmeter (T 206, Transonic Systems) was used to assess aortic flow and a pressure transducer (P $23 \mathrm{ID}$, Statham) to measure aortic pressure (= afterload). In addition, this circuit permitted changing preloading and afterloading conditions. A $3 \mathrm{~F}$ microtip manometer (SPR-249, Millar) was inserted into the balloon to measure left ventricular pressure. For measurement of left ventricular dimensions, sonomicrometry was employed (system 6, Triton): to assess the intraventricular diameter, two piezoelectric crystals were glued to either side of the balloon, and a third crystal was sutured to the left ventricular epicardium for assessment of wall thickness. All blood from the right heart was drained by a cannula placed in the pulmonary artery to measure total coronary blood flow using another ultrasonic flow probe. The difference in arteriovenous oxygen content was continu- ously measured using absorption spectrophotometry (AVOX systems). This system was calibrated on separate occasions against direct measurements provided by a Lex- $\mathrm{O}_{2}-\mathrm{Con}$ analyser.

\section{EXPERIMENTAL PROTOCOL}

After stabilisation of the ventricular function, control conditions were recorded. For assessing the end systolic pressure-volume relation, preloading conditions were changed by increasing left ventricular end diastolic pressure in five to seven $1.5 \mathrm{~mm} \mathrm{Hg}$ steps. Data were recorded when steady state was achieved. The hearts were then subjected to a period of $20 \mathrm{~min}$ normothermic no flow ischaemia. After $30 \mathrm{~min}$ reperfusion, five to seven data sets from different preloading conditions were recorded again. Coronary arterial pressure was held constant ( 80 (SD 2) $\mathrm{mm} \mathrm{Hg}$ ) throughout the protocol. All variables were assessed at constant temperature of $37^{\circ} \mathrm{C}$. The hearts were weighed after the end of the protocol and after drying them for $24 \mathrm{~h}$ at $80^{\circ} \mathrm{C}$.

\section{DATA ACQUISITION}

The following variables were continuously registered with an eight channel forced-ink chart recorder (type 481, Brush): aortic flow, left ventricular pressure, $\mathrm{dP} / \mathrm{dt}$, intraventricular diameter, wall thickness, coronary blood flow, and the difference in arteriovenous oxygen content. The variables were simultaneously stored on magnetic disc after digitising at a sampling rate of $300 \mathrm{~Hz}$ for later analysis.

\section{CALCULATIONS AND STATISTICS}

Haemodynamic data were analysed from an average of six to eight consecutive beats. The end systolic pressure-volume relation, the pressure-volume area (PVA; fig 1A), the relaxation rate $\tau$ (monoexponentially fitting the left ventricular pressure decay), the ventricular stiffness (monoexponentially fitting the end diastolic pressure-volume relation), and the myocardial stiffness ${ }^{22}$ were calculated using a computer program EASYDAT ${ }^{23}$ and, if appropriate, using equations suggested by Mirsky. ${ }^{24}$

Coronary blood flow was normalised to $100 \mathrm{~g}$ wet weight. Coronary resistance was cal-
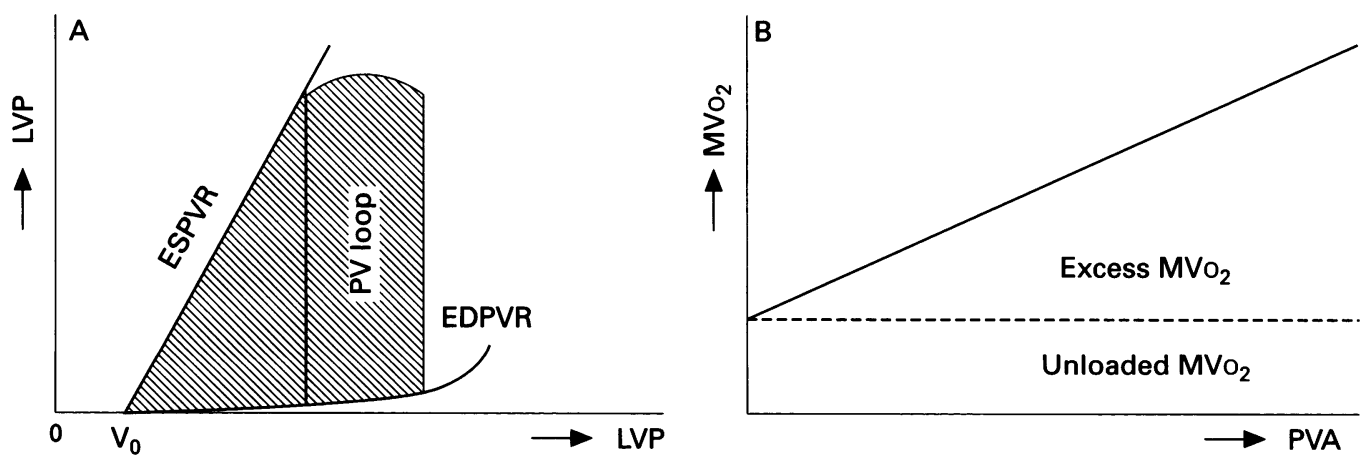

Figure 1 The end systolic pressure-volume relation (ESPVR) was constructed by linear fitting of five to seven pairs of end systolic pressures and volumes that were obtained by preload variation (panel $A$ ). The pressure-volume area (PVA) was assessed from the area circumscribed from the systolic portion of the pressure-volume (PV) loop, the ESPVR and the end diastolic pressure-volume relation (EDPVR). Five to seven $M V \mathrm{O}_{2}$ and $P V A$ pairs were linearly fitted for construction of the $M V \mathrm{O}_{2}-\mathrm{PVA}$ relation (panel $\mathrm{B}$ ). The $\mathrm{MVO} \mathrm{O}_{2}$ intercept of this relation is identical to the $\mathrm{MVO}_{2}$ of the unloaded contraction. 

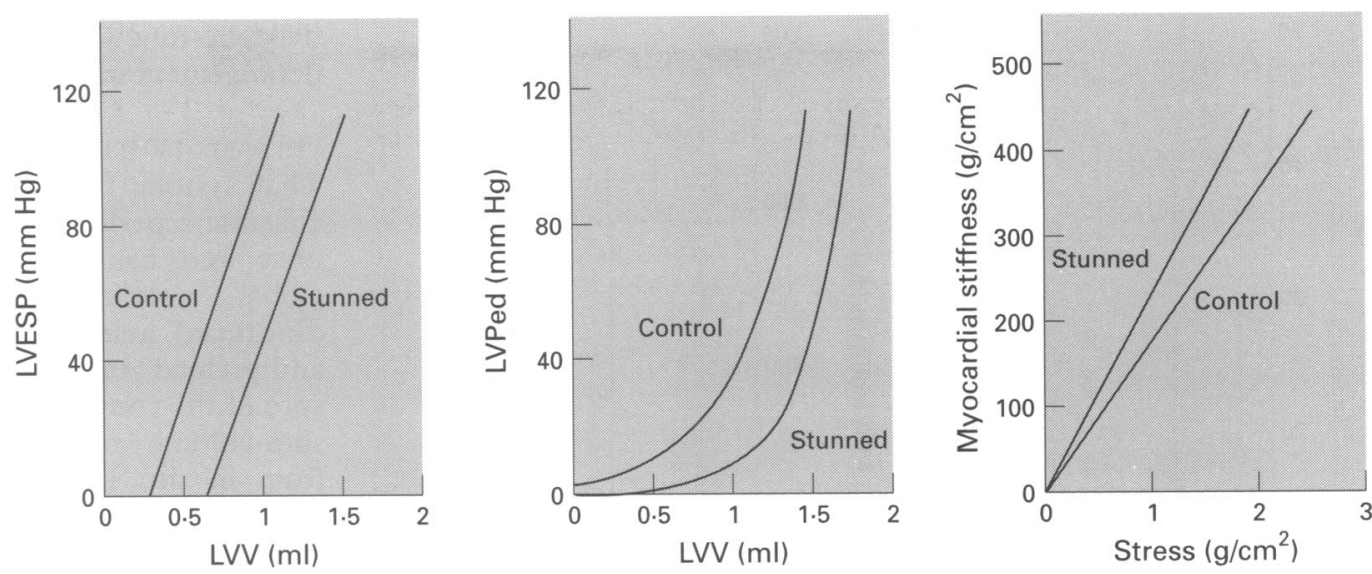

Figure 2 Effects of 20 min global no flow ischaemia on the end diastolic pressure-volume relation (EDPVR; left), the end systolic pressure-volume relation (ESPVR; middle), and the myocardial stiffness in terms of the index $k$ (right). The decrease in the slope of the ESPVR was not pronounced. The rightward shift of the relation (= increased volume intercept $V O)$, however, indicates a decreased global contractile state in the stunned myocardium. The increase in the slope of the EDPVR and of the index $k$ is indicative of an increased stiffness in the globally stunned heart.

culated from coronary arterial pressure and normalised blood flow. $\mathrm{MVO}_{2}$ was calculated according to the Fick principle from normalised coronary blood flow and the difference in arteriovenous oxygen content.

The contractile efficiency was determined as the inverse slope of the $\mathrm{MVO}_{2}$-PVA relation, and the $\mathrm{MVO}_{2}$ for the unloaded contraction was assessed as the intercept of the $\mathrm{MVO}_{2}$ PVA relation with the $\mathrm{MVo}_{2}$-axis (fig 1B). As an index of external efficiency, the ratio of stroke work and myocardial oxygen consumption was determined. The stroke work in turn was calculated from left ventricular peak pressure and stroke volume. If applicable, comparison between normal and postischaemic variables was performed at matched preloading conditions (= intraventricular volume)

Data are presented as mean (SD). Statistical analysis was performed with an IBM compatible personal computer and a statistical software package (SYSTAT). ${ }^{25}$ Nonischaemic and postischaemic data were compared by paired $t$ testing. A $\mathrm{P}$ value of $<0.05$ was considered significant.

\section{Results}

Heart rate was similar in the non-ischaemic and the postischaemic hearts, at 149 (30) $v$ 147 (31) beats/min. However, both the slightly decreased length of systole [66 (31) $v$ $51(9) \mathrm{ms}$ ] and increased length of diastole [146 (30) $v 166$ (41) ms] led to a significant decrease of the relation between systole and diastole by $30 \%[0.44(0.17) v 0.31(0.07)]$. As expected, all systolic global variables were significantly depressed in the postischaemic reperfused hearts: aortic flow was decreased by $76 \%$, LVPmax by $34 \%$, and $\mathrm{dP} / \mathrm{dtmax}$ by $27 \%$. The slope of the end systolic pressurevolume relation (ESPVR) was insignificantly decreased, at 125 (58) $v 138$ (73) $\mathrm{mm} \mathrm{Hg} / \mathrm{ml}$, but the volume axis intercept (Vo) was shifted to the right $[0.30(0.37) v 0.65(0.25) \mathrm{ml}$; fig $2 \mathrm{~A}$ ), additionally indicating impaired contractile state in stunned myocardium. Likewise, global ischaemia impaired early relaxation as measured in terms of both $\mathrm{dP} / \mathrm{dtmin}$ [by $25 \%$ : $-1275(250) v-975(250) \mathrm{mm} \mathrm{Hg} / \mathrm{s}]$, and relaxation rate $\tau$ [by 34\%: 35 (9) $v 47$ (11) $\mathrm{ms}$. The end diastolic pressure was significantly decreased, at 12 (7) $v 19$ (12) $\mathrm{mm} \mathrm{Hg}$ and wall thickness was insignificantly increased by $10 \%$, from $5 \cdot 6(1 \cdot 7)$ to $6 \cdot 2(2 \cdot 2)$ $\mathrm{mm}$. Thus end diastolic wall stress decreased non-significantly from $4.5(3.8)$ to $2.8(2.8)$ $\mathrm{g} / \mathrm{cm}^{2}$. If pre- and postischaemic values were compared not as matched end diastolic volumes but as pressures, postischaemic volumes showed significant increases $[1.3(0.2) v 1.4$ $(0.2) \mathrm{ml}$ ] indicating a rightward shifted end diastolic pressure-volume relation (EDPVR). In this case, wall thickness was insignificantly increased [5.6 (1.4) $v 6.0(1.7) \mathrm{mm}$ ] whereas wall stress remained essentially unchanged $\left[3.3(0.9) v 3.2(1.5) \mathrm{g} / \mathrm{cm}^{2}\right]$.

The slope of the monoexponential EDPVR was steeper in the stunned myocardium, at 8.9 $(5 \cdot 7)$ v $5 \cdot 1(3 \cdot 2) \mathrm{ml}^{-1}$, and the pressure axis intercept was almost unchanged: 1 (1) $v 0$ (1) $\mathrm{mm} \mathrm{Hg}$; fig 2B). This fit therefore showed a rightward shift of the entire EDPVR. Myocardial stiffness was also plotted against stress. The slope (= stiffness constant $k$ ) of this linear relation was significantly increased in the stunned myocardium [179 (34) v 235 (36)] indicating that the postischaemic myocardium was stiffer. Both linear relations intercepted the myocardial stiffness axis at comparable values which were not significantly different from zero: $4 \cdot 1(5 \cdot 1)$ v $2 \cdot 3$ $(3 \cdot 7) \mathrm{g} / \mathrm{cm}^{2}$; fig $2 \mathrm{C}$ ).

Coronary blood flow was decreased, at 82 (32) $v 103(39) \mathrm{ml} / \mathrm{min} / 100 \mathrm{~g}$; this decrease however, did not reach statistical significance. Coronary resistance, in turn, was increased at constantly held coronary arterial pressure. Total myocardial oxygen consumption [40 (9) $v 34(8) \mu \mathrm{l} /$ beat $/ 100 \mathrm{~g}]$ and oxygen consumption for the unloaded contraction $\left[\mathrm{MVO}_{2}\right.$ axis intercept: 26 (9) $v 22(6) \mu \mathrm{l} / \mathrm{beat} / 100 \mathrm{~g}]$ were both non-significantly decreased by $15 \%$ (fig $3 A)$. The pressure-volume area (PVA $=$ measure of total mechanical energy), in contrast, was decreased by $53 \%$, from 570 (280) to 270 

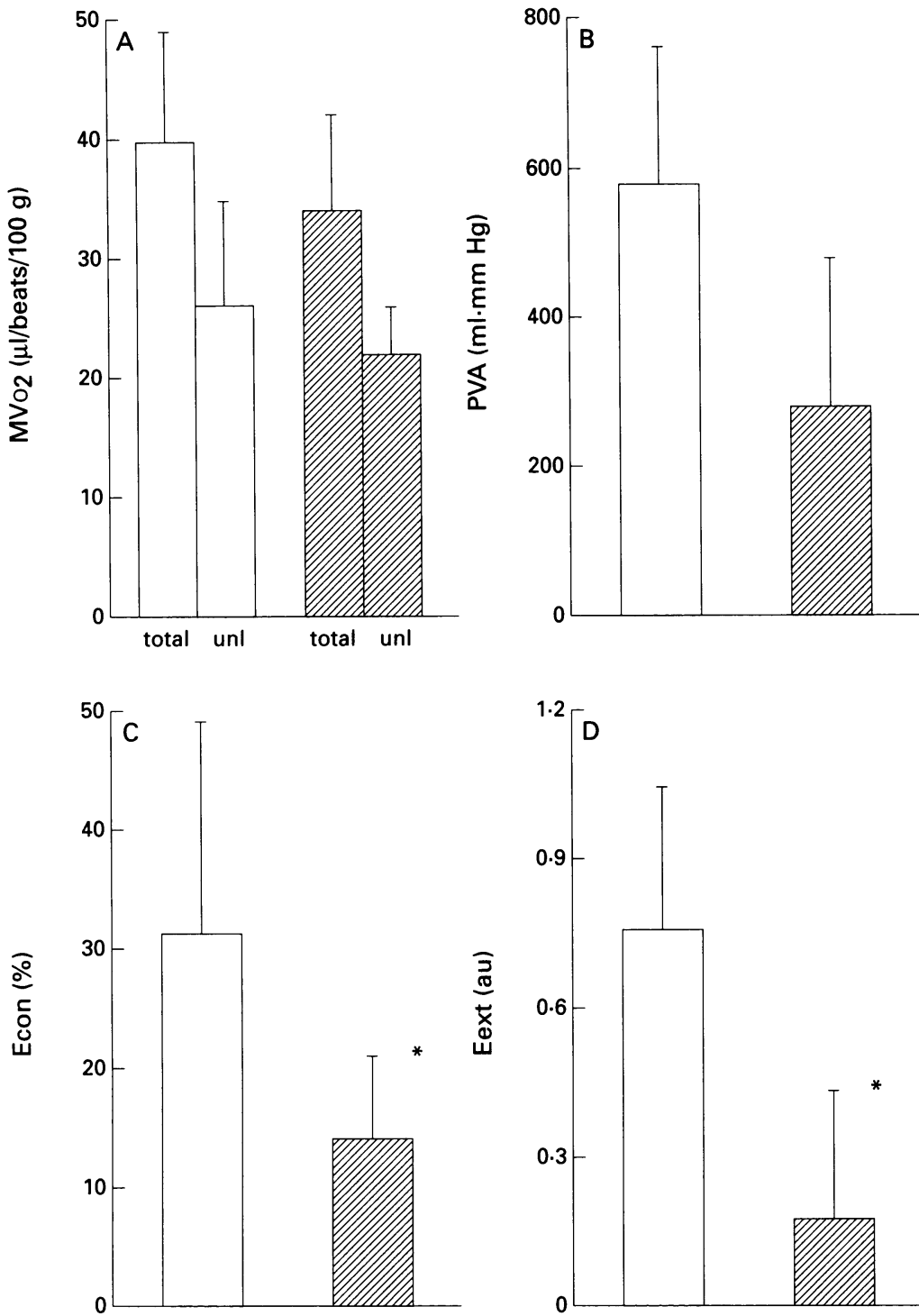

Figure 3 The total myocardial oxygen consumption ( $\mathrm{MVO}_{2}$ tot) and the $\mathrm{MVO}_{2}$ for the unloaded contraction $\left(\mathrm{MVO}_{2}\right.$ unl) were not significantly decreased during myocardial stunning (panel $A$ ). The pressure volume area (PVA) was decreased; however, this decrease was not significant (panel B). Both the contractile efficiency (panel C: Econ) and the external efficiency (panel D: Eext) were significantly decreased in the stunned myocardium. White bars, control; hatched bars, stunning. ${ }^{\star} P<0.05$ control $v$ stunning.

(200) $\mathrm{mm} \mathrm{Hg} / \mathrm{ml} / 100 \mathrm{~g}$; fig 3B. The contractile efficiency (= inverse slope of the $\mathrm{MVO}_{2}-$ PVA relation) was decreased in the stunned myocardium by $55 \%$ [31 (18) $v 14$ (7) \%; fig $3 \mathrm{C}]$, as well as the index of external efficiency by $77 \%[0.75(0.29) v 0.18(0.25)$ arbitrary units; fig 3D].

\section{Discussion}

Systolic and diastolic ventricular properties, coronary resistance, myocardial oxygen consumption, and its relation to systolic function were investigated for normal and postischaemic reperfused myocardium in 15 isolated, blood perfused rabbit hearts. The results from this study emphasise that myocardial stunning presents a whole scenario which not only encompasses systolic function but also diastolic properties and the coronary arterial vascular system. In addition, myocardial oxygen consumption was overproportionately high compared with the impaired systolic and diastolic function, suggesting some metabolic derangement in the stunned myocardium.

\section{SYSTOLIC PROPERTIES}

That systolic function is impaired in postischaemic reperfused myocardium is not a surprise and has often been reported. ${ }^{26}$ Our global systolic measures (LVPmax and $\mathrm{dP} / \mathrm{dtmax}$ ) assessed at unchanged heart rate and preload, as well as a load insensitive measure of the contractile state (end systolic pressure-volume relation), confirm the results from in situ investigations ${ }^{9278}$ which could have been affected by variations in heart rate or preloading conditions.

\section{DIASTOLIC PROPERTIES}

Stunned myocardium is reportedly associated with abnormalities in diastolic performance ${ }^{12} 29$ that might well persist even after restoration of systolic function, ${ }^{30}$ and such diastolic dysfunction may greatly contribute to the clinical manifestation of increased filling pressure. In this study, a global measure of diastolic properties ( $\mathrm{dP} / \mathrm{dtmin}$ ) showed delayed early relaxation in globally stunned myocardium. This measure was not decreased in some other models with regionally stunned myocardium, ${ }^{12}{ }^{13}$ a finding that is of some surprise since contraction of the stunned region might extend into early diastole, ${ }^{10}{ }^{12}$ increasing non-uniformity and thus impeding early relaxation. ${ }^{31}$

In contrast to $\mathrm{dP} / \mathrm{dtmin}$, the rate of isovolumic pressure decay $(\tau)$ reflects not only one instant during early relaxation. Because it is complicated to obtain, this global measure is not so often used. The increase of $\tau$ detected in this study is in accordance with data from canine hearts with regional stunning. ${ }^{31}$ Thus both measures showed impaired early relaxation in globally stunned myocardium.

Studies on regional myocardial stunning show slight increases in the end diastolic pressure (LVPed) and in the unstressed diastolic segment length during early reperfusion..$^{93}$ Comparably, circumferential length was increased at constant LVPed in our globally stunned myocardium as indicated by intraventricular diameter. LVPed in this study was decreased, however, if comparison was made at constant end diastolic volumes. Such segment lengthening ( $=$ creep) is explained as the result of overstretching the akinetic muscle fibres by adjacent non-ischaemic myocardium during ischaemia. ${ }^{913} 33$ Not much is known about myocardial creep. The fact that it is readily reversible within $30 \mathrm{~min}$ by changing the inotropic state suggests that diastolic properties are not entirely passive. ${ }^{9}$ Its close correlation with the recovery of systolic function, in addition, suggests that creep is reversible. ${ }^{9}$ Because in our experiments regional heterogeneities are unlikely to exist, the phenomenon of overstretch might also develop in the globally ischaemic myocardium.

Another approach to describe the effects of ischaemia/reperfusion is based on using passive ventricular properties of the stunned myocardium by employing the end diastolic 
pressure-volume relation (= ventricular stiffness): its increase suggests that the ventricle had stiffened. However, ventricular stiffness varies with pressure, size, and shape, and therefore comparison between ventricles might be inappropriate. ${ }^{24}$ In order to avoid less meaningful comparisons, another approach is based on the stress-strain concept for elastic material and considers elastic stiffness of the myocardium per se. For quantitating this muscle stiffness the index $\mathrm{k}$ was calculated. This index similarly showed increased stiffness.

The increased stiffness could very well be related to an ATP deficiency which is known to induce contracture or even rigor. However, there is experimental evidence that ATP stores in the stunned myocardium are reduced to about $60 \%$ of control after a 15 min coronary artery occlusion ${ }^{34}$ and are readily replenished to about $80 \% . .^{35}{ }^{36}$ Ventricular stiffness, on the other hand, is related to the amount and distribution of collagen. ${ }^{37} 38$ The cytoskeleton within the cells, as well as the residual interactions between thick and thin filaments that exist even in resting muscle cells, also appears to contribute to the diastolic stiffness. ${ }^{39}$ Structural damage of the collagen matrix has been reported to occur in the stunned myocardium. ${ }^{40}$ On the other hand, no such damage in collagen network was observed in conscious dogs. ${ }^{41}$ We did not investigate cardiomyocyte structure and thus cannot determine to what amount changes in the collagen matrix contributed to changes in the stiffness; however, both increased stiffnesses speak against gross collagen matrix damage in our experiments.

The decrease in inotropic state is associated with a similar decrease in the relaxation ability. ${ }^{42}$ The impaired early relaxation, on the other hand, could also be influenced by the increased stiffness ${ }^{43}$ : energy stored in the elastic wall elements during contraction is reduced in the stiffer myocardium and in consequence the energy that brings muscle fibres back into their original position is reduced, ${ }^{44}$ thus slowing relaxation.

The diastolic changes have considerable functional significance: the slowed relaxation shortens the length of diastole thus impeding coronary flow; the increased stiffness in turn, impedes ventricular filling. To maintain stroke volume, the heart needs rightward shifting on the diastolic pressure-volume curve which is energetically unfavourable.

CORONARY RESISTANCE

The reduced subendocardial flow in stunned myocardium ${ }^{182645}$ could reflect either injury of coronary vessels or reduced oxygen demand of dysfunctional myocardium. Because in other studies $^{162146}$ and in this study it was shown that $\mathrm{MVO}_{2}$ is preserved in stunned myocardium, it is likely that coronary resistance is increased after brief periods of ischaemia. On the basis of such increased resistances and significantly reduced coronary reserve in experiments on open chest dogs, the term microvascular stunning was coined. ${ }^{18}$

Potential mechanisms responsible for microvascular stunning include morphological alterations to capillaries and interstitial oedema formation that develops during postischaemic reperfusion. ${ }^{14} 47$ The increase in coronary resistance seen in the present study $(+26 \%)$ is somewhat surprising since the increase in the relation between systole and diastole was significantly decreased, meaning that diastolic length had increased. Still, the increased resistance is in accord with published reports, though it does not permit definite differentiation between these two candidates. Nevertheless, the increased wall thickness at increased inner diameter suggests some oedema formation in the stunned myocardium, a fact that is supported by the slightly decreased ratio between dry and wet weight $(18 \%)$ and by additional experiments on saline perfused rabbit hearts. If the pressure during reperfusion was low, no increase in coronary resistance was observed ${ }^{48}$ in contrast to hearts reperfused at a high perfusion pressures. In other experiments on anaesthetised pigs, we found considerably smaller infarct sizes than in comparable studies, as long as reperfusion after cardioplegia was initiated with low perfusion pressures. ${ }^{49}$ If the endothelial barrier function is lost during ischaemia, it could account for capillary leak and subsequent oedema formation, ${ }^{14} 15$ and it is conceivable that oedema formation, and in turn the extravascular component of the coronary resistance, depend on the perfusion pressure.

At least one study on waking dogs showed that the increased vascular resistance in stunned myocardium could affect ventricular function: after vasodilator induced increases in coronary blood flow, regional function in stunned myocardium was dramatically improved. ${ }^{16}$

It must be remembered that these results hold only for short periods of hypoxia or ischaemia $(<20 \mathrm{~min})$. Under these conditions, the time course of injury to myocytes and endothelial cells seems similar. ${ }^{14}$ After longer periods, the myocardium becomes not only stunned but irreversibly damaged and severe vascular injury occurs, initiating the no flow phenomenon ${ }^{1719}$ and reperfusion haemorrhage. ${ }^{50}$

So far endothelial barrier function has been discussed, but function of the endothelium in regulating regional blood flow has not been mentioned. Endothelium in coronary arteries is damaged after ischaemia and reperfusion. ${ }^{145152}$ Thus the vasodilator effect of nitric oxide is likely to be reduced. On the other hand, the acetylcholine induced relaxation of isolated ${ }^{53}$ and in vivo ${ }^{54}$ coronary arteries is reversed to contraction in the absence of endothelium. Similarly, NO stimulation of vasodilatation caused by acetylcholine, calcium ionophores, or platelets appears to be reduced in the stunned myocardium. ${ }^{51}$ Moreover, inhibition of NO synthesis enhances myocardial stunning in conscious dogs, and this is potentially independent of its effects on blood flow. ${ }^{52}$

\section{OXYGEN CONSUMPTION}

Many studies have shown that $\mathrm{MVO}_{2}$ is pre- 
served in stunned myocardium ${ }^{16214655}$ while mechanical work is depressed. In some studies, the relatively high $\mathrm{MVO}_{2}$ was explained by repair processes taking place in the stunned myocardium. ${ }^{46}$ Increased wall tension within the postischaemic area will play an additional role. In this study, total $\mathrm{MVO}_{2}$ at reduced function was slightly decreased, whereas the oxygen consumption for the unloaded contraction remained essentially unchanged, as was the case in a study on isolated, blood perfused canine hearts. ${ }^{8}$ The $\mathrm{MVO}_{2}$ for the unloaded contraction contains one fraction for basal metabolism and another for excitationcontraction coupling and was shown to increase with increasing, ${ }^{57}$ and to decrease with decreasing, ${ }^{58}$ contractile state. Because an increased basal metabolism in stunned myocardium was also made responsible for its high energy demand, it is a certain shortcoming of this study that, owing to the extremely small blood flow after cardiac arrest, we were unable to measure the basal $\mathrm{MVO}_{2}$ with our spectrophotometric technique. If, on the other hand, basal $\mathrm{MVO}_{2}$ does not differ appreciably between normal and stunned myocardium, ${ }^{821}$ the maintained $\mathrm{MVO}_{2}$ for the unloaded contraction would suggest that the fraction for excitation-contraction coupling is inadequately high for the depressed contractile state in stunned myocardium, ${ }^{21}$ and in fact impairment in calcium handling by the sarcoplasmic reticulum has been held responsible. ${ }^{2159}$

\section{EXTERNAL EFFICIENCY}

The depressed function and inadequately high $\mathrm{MVO}_{2}$ make the postischaemic myocardium energetically inefficient. ${ }^{202160}$ Little is known about the time course, extent, and consequences of this inefficiency. ${ }^{5661}$ Possible causes of the persisting dysfunction include uncoupling between substrate metabolism and energy production, accelerated but useless energy drainage, ${ }^{46}$ or some impairment between energy transfer and the function of contractile proteins. ${ }^{461}$ Increased ATP requirements for force generation by the myofilaments were also held responsible for inadequate $\mathrm{MVO}_{2}{ }^{62}$ In the present study, the relation between stroke work and $\mathrm{MVO}_{2}$ (external efficiency) was drastically reduced in the postischaemic group, a finding that is in good accord with published reports. ${ }^{2162}$

\section{CONTRACTILE EFFICIENCY}

The pressure-volume area (PVA, fig 1A) as a measure of the total mechanical work has proven to be a useful tool for investigation of cardiac dynamics. ${ }^{6364}$ The relation between $\mathrm{MVO}_{2}$ and the PVA has been shown to be linear in canine hearts ${ }^{57}$ and to describe the contractile efficiency. The $\mathrm{MVO}_{2}$-PVA framework allows partitioning of the $\mathrm{MVO}_{2}$ in one fraction that is associated with ventricular work (PVA dependent) and another that is non-workrelated. Hence these two aspects can be separated. Contractile efficiency of the stunned myocardium was clearly decreased in the present study. This result would fit into the concept that attributes the inefficiency in stunned myocardium to abnormalities in the contractile process ${ }^{21}$ or to some impairment between energy transfer and function of contractile proteins. ${ }^{46}$

\section{SUMMARY}

In the assessment of clinical postischaemic situations, it is definitely helpful to remember that the concept of myocardial stunning comprises multiple levels. Brief episodes of ischaemia do not only induce systolic stunning. Diastolic stunning might, in turn, contribute to the systolic postischaemic dysfunction, and changes in passive diastolic properties need distinct attention. The increase in coronary resistance seems to result from an increased capillary permeability and subsequent oedema, and probably from impaired vasodilator ability of the endothelium. The increased resistance could, in part, impede the oxygen supply and thus also contribute to functional impairment. The almost maintained $\mathrm{MVO}_{2}$ for the unloaded contraction suggests some impairment in excitationcontraction coupling, and both reduced efficiencies are indicative for an impaired $\mathrm{O}_{2}$ utilisation of the contractile apparatus which we propose should be called metabolic stunning. The increased coronary resistance and the $\mathrm{MVO}_{2}$ paradox have to be kept in mind if function in the stunned myocardium is augmented after drugs or during exercise; because both interventions are capable inducing a mismatch between $\mathrm{O}_{2}$ demand and $\mathrm{O}_{2}$ supply, initiation of repetitive stunning is likely.

The study was partly supported by the German Research Foundation (DFG; SFB 242:C7; Coronary Heart Disease, Düsseldorf). The authors are greatly indebted to $\mathrm{Ms} N$ Palomero-Gallagher (MSc Bio) for reading and correcting the manuscript. We wish to thank cand math Brieden for upgrading EASYDAT, Mrs E Vasilescu for excellent secretarial help, and F Nickel for computer support.

1 Braunwald E, Kloner RA. The stunned myocardium: prolonged, postischemic ventricular dysfunction. Circulation 1982;66:1146-9.

2 Heyndrickx GR, Millard RW, McRitchie RJ, Maroko PR, Vatner SF. Regional myocardial functional and electrophysiological alterations after brief coronary artery occlu-
sion in conscious dogs. $f$ Clin Invest 1975;56:978-85.

3 Hearse DJ. Stunning: a radical re-view. Cardiovasc Drugs Ther 1991:5:853 76 .

4 Bolli R. Myocardial "stunning" in man. Circulation 1992;86:1671-91.

5 Opie LH and du Toit EF. Postischemic Stunning: The two-phase model for the role of calcium as pathogen. $\mathcal{f}$ Cardiovasc Pharmacol 1992;20(suppl 5):1-4.

6 Heusch G. The relationship between regional blood flow and contractile function in normal, ischemic, and reperfused myocardium. Basic Res Cardiol 1991;86:197-218.

7 Marban E. Myocardial stunning and hibernation. Circulation 1991;83:681-8.

8 Ohgoshi Y, Goto Y, Futaki S, Yaku H, Kawaguchi O, Suga $H$. Increased oxygen cost of contractility in stunned myocardium of dog. Circ Res 1991;69:975-88.

9 Glower DD, Schaper J, Kapas JS, Hoffmeister HM, Schaper W, Spratt JA, et al. Relation between reversal of diastolic creep and recovery of systolic function after ischemic myocardial injury in conscious dogs. Circ Res 1987;60:850-60.

10 Przyklenk K, Patel B, Kloner RA. Diastolic abnormalities of postischemic "stunned" myocardium. Am $f$ Cardiol of postischemic

11 Kloner RA, Przyklenk K, Patel B. Altered myocardial states. Am $\mathcal{F}$ Med 1989;86(suppl 1A):14-22.

12 Ehring T, Schulz R, Schipke JD, Heusch G. Diastolic dysfunction of stunned myocardium. Am $\mathcal{F}$ Cardiovasc Pathol function of stun

13 Charlat ML, O'Neill PG, Hartley CJ, Roberts R, Bolli R. Prolonged abnormalities of left ventricular diastolic wall thinning in the "stunned" myocardium in conscious dogs: time course and relation to systolic function. $\mathcal{F} \mathrm{Am}$ Coll Cardiol 1989;13:185-94.

14 Sunnergren KP, Rovetto MJ. Myocyte and endothelial injury with ischemia reperfusion in isolated rat hearts. Am f Physiol 1987;252:H1211-7. 
15 Svendsen JH, Bjerrum PJ, Haunso S. Myocardial capillary permeability after regional ischemia and reperfus

16 Laxson DD, Homans DC, Dai X-Z, Sublett E, Bache RJ. Oxygen consumption and coronary reactivity in postischemic myocardium. Circ Res 1989;64:9-20.

17 Babbitt DG, Virmani R, Forman MB. Intracoronary adenosine administered after reperfusion limits vascular injury after prolonged ischemia in the canine model. injury after prolonged ischemitat

18 Bolli R, Triana JF, Jeroudi MO. Prolonged impairment of coronary vasodilation after reversible ischemia. Evidence for microvascular stunning. Circ Res 1990;67:332-43.

19 Jeremy RW, Links JM, Becker LC. Progressive failure of coronary flow during reperfusion of myocardial infarction: documentation of the no reflow phenomenon with positron emission tomography. F Am Coll Cardiol 1990; 16:695-704.

20 Allen BS, Rosenkranz EP, Buckberg GD, Vinten-Johansen J, Okamoto F, Leaf J. Studies of controlled reperfusion after ischemia. VII. High oxygen requirements of dyskinetic cardiac muscle. 7 Thorac Cardiovasc Surg 1986; 92:543-52.

21 Laster SB, Becker LC, Ambrosio G, Jacobus WE. Reduced aerobic metabolic efficiency in globally "stunned" myocardium. $¥ \mathrm{Mol}$ Cell Cardiol 1989;21:419-26.

22 Nizolek JA, Jacob R, Gilmore JP. Insignificance of activation pathway on myocardial oxygen consumption. tion pathway on myocardial

23 Britz M, Sunderdiek U, Schipke JD. Easydat: a computer program for data acquisition and processing [abstr]. Pflugers Arch 1992;420(suppl 1):R 140.

24 Mirsky I. Elastic properties of the myocardium: a quantitative approach with physiological and clinical applications In: Berne R, Sperelakis N, Geiger SR, eds. Handbook of physiology - the cardivascular system. Bethesda: American Physiological Society, 1979:497-531.

25 Wilkinson L. REGM: a multivariate general linear hypothesis program. Am Stat 1980;34:182

26 Bolli R, Zhu W, Thornby J,, O'Neill PG, Roberts R. Time course and determinants of recovery of function after reversible ischemia in conscious dogs. Am $\not{f}$ Physiol 1988;254:H112-4.

27 Preuss KC, Gross GJ, Brooks HL, Warltier DC. Time course of recovery of "stunned" myocardium following variable periods of ischemia in conscious and anesthetized dogs. Am Heart $f 1987 ; 114: 696-703$

28 Triana JF, Xiao-Ying Li, Jamaluddin U, Thornby JI, Bolli R Postischemic myocardial "stunning": identification of major differences between the open-chest and the conmajor differences between the open-chest and the conscious dog and evaluation of the oxygen radical hy
sis in the conscious dog. Circ Res 1991;69:731-47.

29 Heyndrickx GR, Paulus WJ, Vantrimpont P, Vogelaers D. Left ventricular diastolic stunning coincides with regiona systolic asynchrony between normal and stunned myocardium. Circulation 1989;80(suppl II):II-97.

30 Wijns W, Serruys PW, Slager CJ, Grimm J, Krayenbueh $\mathrm{HP}$, Hugenholtz PG, et al. Effect of coronary occlusion during percutaneous transluminal angioplasty in human on left ventricular chamber stiffness and regional diastolic pressure-radius relations. $\mathcal{F} \mathrm{Am}$ Coll Cardiol 1986;7 455-63.

31 Kumada T, Karliner JS, Pouleur H, Gallagher KP, Shirato $\mathrm{K}$, Ross J. Effects of coronary occlusion on early ventricular diastolic ever

32 Hanaki Y, Sugiyama S, Ajioka M, Kondo T, Fukushima Ozawa $\mathrm{T}$. Acceleration of recovery of mitochondrial function after coronary reperfusion by various coronary function after coronary reperfusion by various coronary
dilating drugs in canine heart. $₹$ Cardiovasc Pharmacol dilating drugs in

33 Hess OM, Osakada G, Lavelle JF, Gallagher KP, Kemper WS, Ross J. Diastolic myocardial wall stiffness and ventricular relaxation during partial and complete coronary occlusions in the conscious dog. Circ Res 1983;52: $387-400$.

34 Reimer KA, Hill ML, Jennings RB. Prolonged depletion of ATP because of delayed repletion of the adenine nucleotide pool following reversible myocardial ischemic injury in dogs. Adv Myocardiol 1981;4:395-407.

35 Ambrosio G, Jacobus WE, Bergman CA, Weisman HF, Becker LC. Preserved high energy phosphate metabolic reserve in globally stunned hearts despite reduction of basal ATP content and contractility. $7 \mathrm{Mol}$ Cell Cardiol 1987;219:953-64.

36 Guth BD, Martin JF, Heusch G, Ross J. Regional myocardial blood flow, function and metabolism using phosphorus-31 nuclear magnetic resonance spectroscopy during ischemia and reperfusion. $¥ \mathrm{Am}$ Coll Cardiol 1987;10: 673-81.

37 Borg TK, Ranson WF, Moslehy FA, Caulfield JB. Structural basis of ventricular stiffness. Lab Invest 1981; 44:49-54.

38 Weber KT. Cardiac interstitium in health and disease: the fibrillar collagen network. F Am Coll Cardiol 1989;13: 1637-52.

39 Katz AM. Physiology of the heart. New York: Raven Press, 1992

40 Zhao M, Zhang H, Robinson TF, Factor SM, Sonnenblick EH, Eng C. Profound structural alterations of the extracellular collagen matrix in postischemic dysfunctional ("stunned") but viable myocardium. $₹ \mathrm{Am}$ Coll Cardiol ("stunned") but

41 Whittaker P, Boughner DR, Kloner RA, Przyklenk K. Stunned myocardium and myocardial collagen damage: Differential effects of single

42 Cohn PF, Liedtke AJ, Serur J, Sonnenblick EH, Urschel $\mathrm{CW}$. Maximal rate of pressure fall (peak negative dP/dt) during ventricular relaxation. Cardiovasc Res 1972;6: 263-7.

43 Mathey D, Bleifeld W, Franken G. Left ventricular relaxation and diastolic stiffness in experimental myocardial infarction. Cardiovasc Res 1974;8:583-92.

44 Burton AC. Physiology and biophysics of the circulation: an introductory textbook. Chicago: Year book medical publishers, 1965.

45 Heyndrickx GR, Baig H, Nellens P, Leusen I, Fishbein MC, Vatner SF. Depression of regional blood flow and wall thickening after brief coronary occlusions. $A m \mathcal{F}$ Physiol 1978;234:H653-9.

46 Liedtke AJ, De Maison L, Eggleston AM, Cohen LM, Nellis SA. Changes in substrate metabolism and effects of excess fatty acids in reperfused myocardium. Circ Res of excess fatty acids

47 Jennings RB, Reimer KA. Factors involved in salvaging ischemic myocardium: effects of reperfusion of arterial blood. Circulation 1983;68(suppl I):25-36.

48 Helmes C, Sunderdiek U, and Schipke JD. Coronary resistance in isolated rabbit hearts during control and reperfusion after brief ischemia [abstr]. Pflugers Arch 1994 426(suppl): $R$ 127.

49 Sunderdiek U, Kantartzis M, Souvatzis X, Peter B, Schipke JD. Regional ischemia and reperfusion: the effect of myocardial protection on the infarct size in the pig [abstr]. Pflugers Arch 1991;419(suppl 1):170.

50 Fishbein MC, Y-Rit J, Lando U, Kanmatsuse K, Mercier JC, Ganz W. The relationship of vascular injury and myocardial hemorrhage to necrosis after reperfusion. Circulation 1980;62:1274-9.

51 Wallace A. Do deficiencies of endothelial derived relaxing factor contribute to myocardial stunning? $\mathcal{F}$ Cardiac Surg 1995;8:325-8.

52 Hasebe N, Shen YT, Vatner SF. Inhibition of endothelium-derived relaxing factor enhances myocardial stunning in conscious dogs. Circulation 1993;88:2862-71.

53 Furchgott RF, Zawadzki JV. The obligatory role of endothelial cells in the relaxation of arterial smooth muscle by acetylcholine. Nature 1980;288:373-6.

54 Schipke JD, Heusch G, Deussen A, Thaemer V. Acetylcholine induces constriction of epicardial coronary arteries in anesthetized dogs after removal of endothelium. Drug Res 1985;35:926-9.

55 Krukenkamp IB, Silverman NA, Sorlie D, Pridjian A Feinberg H, Levitsky S. Characterization of postischemic myocardial oxygen utilization. Circulation 1986;74(supp III):III-125-9.

56 Furukawa S, Bavaria JE, Kreiner G, Edmunds LH Relationship between total mechanical energy and oxygen consumption in the stunned myocardium. Ann gen consumption in the
Thorac Surg 1990;49:543-9.

57 Suga H, Hisano R, Goto Y, Yamada O, Igarashi Y. Effect of positive inotropic agents on the relation between oxygen positive inotropic agents on the relation between oxygen consumption and systolic pressure-volum

58 Suga $\mathrm{H}$, Goto $\mathrm{Y}$, Yasamura $\mathrm{Y}$, Nozawa $\mathrm{T}$, Futaki $\mathrm{S}$, Tanaka $\mathrm{N}$, et al. $\mathrm{O}_{2}$ consumption of dog heart under decreased coronary perfusion and propranolol. $\mathrm{Am} \mathscr{f}$ Physiol 1988;254:292-303.

59 Krause SM, Jacobus WE, Becker LC. Alterations in cardiac sarcoplasmic reticulum calcium transport in the postischemic "stunned" myocardium. Circ Res 1989;65 526-30.

60 Sako EY, Kingsley-Hickmann PB, From AHL, Foker JE Ugurbil K. ATP synthesis kinetics and mitochondria function in the postischemic myocardium as studied by ${ }^{31} \mathrm{P}$ NMR. F Biol Chem 1988;263:10600-7.

61 Burkhoff D, De Tombe PP, Hunter WC, Kass DA Contractile strength and mechanical efficiency of left ventricle are enhanced by physiological afterload. $A m \mathcal{F}$ Physiol 1991;260:H569-78.

62 Burkhoff $\mathrm{D}$. Myocardial energetics and the postischemic heart. Ann Thorac Surg 1990;49:525-7.

63 Gibbs CL, Chapman JB. Cardiac mechanics and energetics: chemomechanical transduction in cardiac muscle. Am $\mathcal{f}$ Physiol 1985;249:H199-206.

64 Suga H. Ventricular energetics. Physiol Rev 1990;70: 247-77. 